\title{
EXAMINATION OF BACKGROUND CONTAMINATION LEVELS FOR GAS COUNTING AND AMS TARGET PREPARATION IN TRONDHEIM
}

\author{
STEINAR GULLIKSEN and METTE S. THOMSEN
}

Radiological Dating Laboratory, The Norwegian Institute of Technology, N-7034 Trondheim Norway

\begin{abstract}
The Radiological Dating Laboratory in Trondheim relatively often dates samples with ages $>30$ ka BP. Contaminated background materials are known to affect the accuracy of very old dates. We have found, by measurements of different materials, that such contamination is small when using our conventional gas proportional counting (GPC) system. We have also studied contamination levels of our target preparation for ${ }^{14} \mathrm{C}$ accelerator mass spectrometry (AMS) dating in Uppsala. A significant lower background is obtained for Icelandic double spar than for marbles, probably due to a crystal structure of the double spar that is more insensitive to contaminating processes. The background for combusted samples is at the same level as for samples of double spar, indicating that additional ${ }^{14} \mathrm{C}$ contamination due to combustion is negligible. Dates obtained on interstadial samples (T $>30 \mathrm{ka} \mathrm{BP})$ by both GPC and AMS agree well.
\end{abstract}

\section{INTRODUCTION}

Accurate determination of background levels is extremely important for dating interstadial samples older than $30 \mathrm{ka}$ BP by both gas proportional counting (GPC) and accelerator mass spectrometry (AMS).

For $\beta$-decay counting, background levels are assessed by measuring sample materials assumed to have a negligible content of ${ }^{14} \mathrm{C}$. However, such measurements do not distinguish between ${ }^{14} \mathrm{C}$ contamination in the sample and the genuine background of the counting equipment itself. AMS dating of background samples has sometimes revealed relatively high contamination levels (Beukens 1990). This could imply that laboratories using such background samples systematically obtain ages that are too old for interstadial samples. We relatively often date interstadial samples, and we found it therefore necessary to examine our background samples for contamination.

AMS samples from Norwegian submitters are now prepared at the Radiological Dating Laboratory in Trondheim and measured at the Uppsala Tandem Accelerator Laboratory. Graphite samples $(\sim 1$ $\mathrm{mg} \mathrm{C}$ ) are produced by catalytic reduction of $\mathrm{CO}_{2}$ with $\mathrm{H}_{2}$, using iron as catalyst. The major background contribution for AMS dating is sample contamination during chemical preparation, whereas the inherent background of the accelerator is negligible. Most important in dating interstadial samples is keeping background due to sample preparation low and reproducible. Thus, we have made a series of AMS measurements on background samples used in our counters. We also measured the ${ }^{14} \mathrm{C}$ concentration of several other materials known to be older than $80 \mathrm{ka}$ BP. These types of material, all commonly submitted for dating, were used to determine whether the ${ }^{14} \mathrm{C}$ concentration of chemically prepared background samples is dependent on the actual sample material.

Finally, we dated a number of interstadial samples $(\mathrm{T}>30 \mathrm{ka} \mathrm{BP})$ both by decay counting and by AMS, and we find no deviation in the ages obtained by the two techniques.

\section{GAS COUNTING}

\section{Materials and Methods}

A commercially available $\mathrm{CO}_{2}$ gas produced by combustion of natural gas is, according to Beukens (1990), an adequate ${ }^{14} \mathrm{C}$-free reference (Matheson ${ }^{\$}$, U.S.A.; 1 liter glass vessels; Beukens, personal communication). Great care was taken to ensure that gas for our proportional counter (copper wall, 
1.5 liter volume, $200 \mathrm{kPa} \mathrm{CO}_{2}$ ) was obtained from exactly the same source. Measurements on this gas were made in sequence with the IAEA C-1 reference material (Carrara marble) (Rozanski et al. 1992) and Icelandic double spar, which, according to our AMS measurements, should be an excellent background material. We measured two preparations of the Carrara marble, one sieved to obtain the coarsest fraction, with the outer $20 \%$ etched away, the other, a finer fraction with no pretreatment. For all the other samples, the outer $25 \%$ was removed before $\mathrm{HCl}$ hydrolysis.

Even rather low contamination levels would be significant to dates at the margin of ${ }^{14} \mathrm{C}$ dating capability. Thus, in order to obtain adequate detection sensitivity, we used several weeks of counting time. Of course, it is also necessary to evaluate the stability of the counting equipment, for measurements of the precision required here. Gulliksen and Nydal (1979) showed earlier that about $40 \%$ of our counter background is cosmic-ray induced. Thus, we made a special study of background dependence on barometric pressure to determine the correction factor for the particular counter in use. An analysis of variability within the counting period for each sample did not reveal variances in excess of those caused by counting statistics.

We have found that contributions from possible longer-term fluctuations due to, e.g., drift of electronics and atmospheric temperature variations (Håkansson 1980) are too small to be relevant. We avoided radon contamination by storing gases for a minimum of six weeks before counting.

\section{Results and Discussion}

Table 1 shows contamination levels calculated by assuming the counter background to be equal to the count rate obtained for the $\mathrm{CO}_{2}$ gas. We detected no significant contamination for Icelandic double spar nor for Carrara marble. Unfortunately, a freshly prepared sample of our regular background material (Fauske marble) was unavailable at the time of measurements. We used marble cut several years ago and give two sets of values for this material. The last row of Table 1 (Fauske (contam.)) shows the result of measurements, directly preceding the others, on gas that had passed through numerous cycles in and out of our counters. This handling has obviously caused significant contamination of the gas. The other less, but still contaminated value $0.17 \pm$ $0.07 \mathrm{pMC}$ ) of Fauske marble is derived from earlier weekly measurements on the same gas during a period when contamination was expected to be insignificant. A new sample of freshly cut Fauske marble has recently yielded count rates that agree perfectly with those of $\mathrm{Matheson}^{\mathrm{CO}} \mathrm{O}_{2}$ gas. Thus, poor long-term storage of calcite material in the laboratory is probably the cause of slightly higher ${ }^{14} \mathrm{C}$ concentration of Fauske marble cut several years ago. However, the Icelandic double spar, which suffered similar storage conditions, showed no ${ }^{14} \mathrm{C}$ content and thus seems to be less sensitive to contamination.

Table 1 also includes an age example which demonstrates the effect of applying the count rates obtained on different background materials when calculating the age of a $40 \mathrm{ka}$ old sample. This

TABLE 1. Measurements on Different Background Materials $-\mathrm{CO}_{2}$ Gas Counting

\begin{tabular}{lcccc}
\hline Sample material & $\begin{array}{c}\text { Count rate } \\
(\mathrm{cpm})\end{array}$ & $\begin{array}{c}\text { Count rate } \\
\text { difference }(\mathrm{cpm})\end{array}$ & pMC & $\begin{array}{c}\text { Age example } \\
\text { (yr BP) }\end{array}$ \\
\hline $\mathrm{CO}_{2}$ from natural gas & $0.727 \pm 0.008$ & & & 40,000 \\
Icelandic double spar & $0.734 \pm 0.005$ & $0.007 \pm 0.009$ & $0.05 \pm 0.06$ & 40,570 \\
Carrara (80\%) & $0.738 \pm 0.009$ & $0.011 \pm 0.012$ & $0.07 \pm 0.08$ & 40,900 \\
Carrara (100\%) & $0.747 \pm 0.014$ & $0.020 \pm 0.016$ & $0.13 \pm 0.11$ & 41,720 \\
Fauske marble & $0.753 \pm 0.008$ & $0.026 \pm 0.011$ & $0.17 \pm 0.07$ & 42,320 \\
Fauske (contam.) & $0.774 \pm 0.007$ & $0.047 \pm 0.011$ & $0.31 \pm 0.07$ & 44,870 \\
\hline
\end{tabular}


shows that by using the supposedly uncontaminated Fauske marble as background, a significant age shift of the order of $2 \mathrm{ka}$ is introduced.

\section{AMS ${ }^{14} \mathrm{C}$ BACKGROUND}

\section{Materials and Methods}

AMS dating of different types of material enables us to determine the ${ }^{14} \mathrm{C}$ contamination of samples produced by combustion or acid hydrolysis, and whether the chemical background varies for the different materials. Besides the materials used for determining background levels by GPC, the AMS investigation also included an Eemian mollusk shell (Frøya, Sør-Trøndelag, Norway), a whale bone (Beaufort Sea, Alaska (Stafford et al. 1987)), two samples of interglacial wood from Norway (Åstbrua, Hedmark and Hensmoen, Buskerud), and a monospecific sample of foraminifera ( $8.2 \mathrm{mg}$ of Elphidium excavatum). The foraminifera were handpicked from the Brunhes/Matuyama boundary of a sediment core from the North Sea.

The background samples were prepared by standard methods applied to AMS samples submitted for dating: wood $-0.12 \mathrm{M} \mathrm{HCl}(4 \mathrm{~h}), 0.25 \mathrm{M} \mathrm{NaOH}(8 \mathrm{~h}), 0.12 \mathrm{M} \mathrm{HCl}(4 \mathrm{~h})$, all solutions at $90^{\circ} \mathrm{C}$; bone - gelatin extraction by a modified Longin method (Larsen et al. 1987); foraminifera $-3 \times 15$ min ultrasonication with distilled water; other carbonates - at least $25 \%$ of the sample removed by etching in $0.5 \mathrm{M} \mathrm{HCl}$.

Wood and bone samples were converted to $\mathrm{CO}_{2}$ by combustion with water (Thomsen \& Gulliksen 1992), whereas carbonates were hydrolyzed with $85 \%$ phosphoric acid. The $\mathrm{CO}_{2}$ was then reduced to graphite (Vogel et al. 1984) on $\sim 1 \mathrm{mg}$ Fe powder placed in the well of a copper target holder. The targets were mounted in a 20-position sample wheel for the ion source of the Uppsala tandem accelerator (Possnert 1990).

\section{Results and Discussion}

Table 2 shows the weighted average ${ }^{14} \mathrm{C}$ concentrations of at least two $\sim 1 \mathrm{mg} \mathrm{C}$ targets (only one for TUa-108 and -174). We made no correction for machine background. The interval was at least one month between each measurement of individually produced targets from the same sample.

We saw no difference between the ${ }^{14} \mathrm{C}$ concentration of the targets produced from $\mathrm{CO}_{2}$ of natural gas or Icelandic double spar, which agrees with the results obtained by GPC. This also indicates that no ${ }^{14} \mathrm{C}$ contamination is introduced during acid hydrolysis of AMS samples.

TABLE 2. Measurements on Different Background Materials - AMS Technique

\begin{tabular}{|c|c|c|c|}
\hline Sample material & TUa* no. & $\mathrm{pMC}$ & $\begin{array}{c}\text { Apparent age } \\
\text { (yr BP) }\end{array}$ \\
\hline $\begin{array}{l}\mathrm{CO}_{2} \text { from natural gas } \\
\text { Icelandic double spar } \\
\text { Marble (Fauske, Norway) } \\
\text { Marble (Carrara, IAEA-C1) } \\
\text { Mollusk shell (Frøya, Norway) } \\
\text { Foraminifera (North Sea) } \\
\text { Interglacial wood (Åstbrua, Norway) } \\
\text { Whale bone (Beaufort Sea, Alaska) } \\
\text { Interglacial wood (Hensmoen, Norway) }\end{array}$ & $\begin{array}{l}-200 \\
-201 \\
-202 \\
-108 \\
-203 \\
-174 \\
-76 \\
-121 \\
-204\end{array}$ & $\begin{array}{l}0.17 \pm 0.03 \\
0.18 \pm 0.03^{* *} \\
0.51 \pm 0.08^{* *} \\
0.54 \pm 0.07 \\
0.57 \pm 0.06 \\
0.32 \pm 0.06 \\
0.16 \pm 0.03 \\
0.18 \pm 0.03 \\
0.38 \pm 0.02^{* *}\end{array}$ & $\begin{array}{l}51,200 \\
50,800 \\
42,400 \\
41,900 \\
41,500 \\
46,100 \\
51,800 \\
50,800 \\
44,800\end{array}$ \\
\hline
\end{tabular}

*Samples graphitized in Trondheim ( $\mathrm{T}$ ) and measured in Uppsala (Ua)

**The standard error of $5{ }^{14} \mathrm{C}$ measurements; other errors quoted are based on counting statistics of two measurements. 
However, we found a significant difference between the ${ }^{14} \mathrm{C}$ concentration of the two types of marble (ca. $0.5 \mathrm{pMC})$ and Icelandic double spar $(0.18 \mathrm{pMC})$. Figure 1 shows the apparent age of each target made from double spar (A) and marble (B). Although the scatter of the ages is larger than that expected from counting statistics, the difference in ${ }^{14} \mathrm{C}$ concentration for the two types of carbonate crystals is quite clear. A higher sensitivity to contamination processes may be expected for marbles because of their small grain structure, which probably is highly porous along the numerous grain boundaries. The situation is quite different for the large crystal structure of Icelandic double spar.
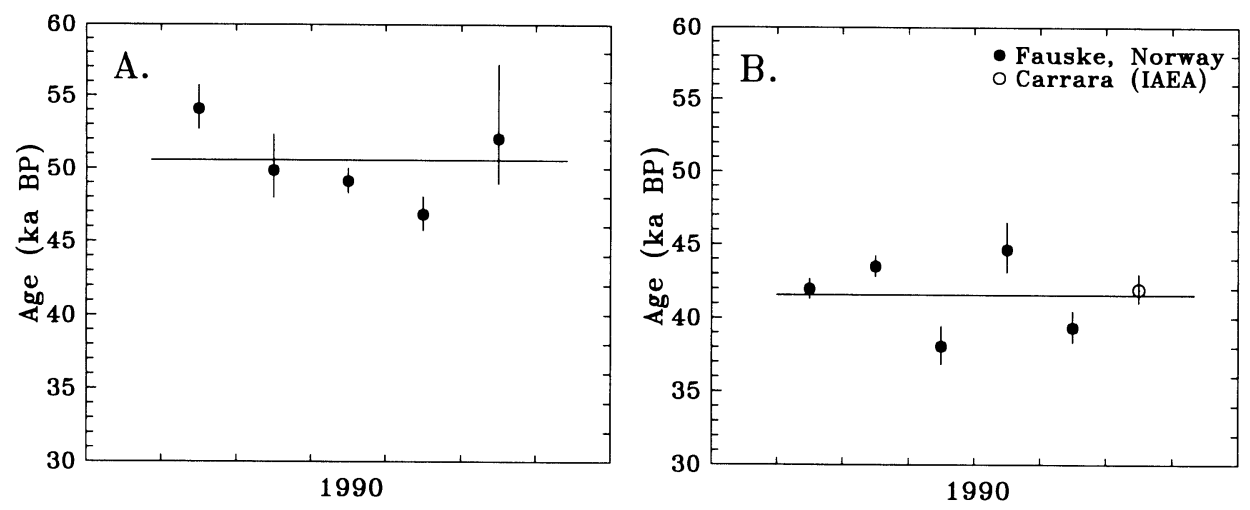

Fig. 1. A. Double spar; B. Marble samples measured during a six-month period in 1990

Table 2 also shows that the Eemian mollusk shell has a ${ }^{14} \mathrm{C}$ concentration of $0.57 \mathrm{pMC}$, comparable to the marble values, whereas the foraminifera sample surprisingly showed a lower ${ }^{14} \mathrm{C}$ concentration than the mollusk shell. However, the foraminifera sample was collected just before sample preparation, whereas the mollusk shell had been stored for more than one year. These results indicate that, along with crystal structure, storage conditions may be of importance for old samples. This is also supported by recent AMS measurements on freshly cut Fauske marble yielding ${ }^{14} \mathrm{C}$ concentrations equal to the double spar sample, and in agreement with the GPC results.

The background targets produced by combustion of wood (TUa-76) and gelatin from a whale bone (TUa-121) show a ${ }^{14} \mathrm{C}$ concentration comparable to the double spar sample and the Matheson $\mathrm{CO}_{2}$ gas. Contrary to observations of other AMS laboratories (Vogel, Nelson \& Southon 1987; Hedges et al. 1989), no significant background is introduced in our combustion system. The ${ }^{14} \mathrm{C}$ concentration for TUa-204 is, however, a factor of two higher. This sample was measured conventionally 20 years ago (Gulliksen, Nydal \& Løvseth 1975), to >47 ka BP (T-743/II; 2 o) and until now, has been stored in a non-air-tight plastic bag in the laboratory. TUa-76 was sampled from glaciolacustrine clay about one year ago, and has, since, been stored in a glass vial. Thus, storage conditions may also be important for wood samples with ages close to background. We plan to investigate this further by dating the cellulose fraction of TUa-204.

\section{COMPARISON OF DATES OBTAINED BY GPC AND AMS}

In order to compare the two dating techniques for materials of interstadial age, we dated some samples ( $\mathrm{T}>30 \mathrm{ka} \mathrm{BP}$ ) by both GPC and AMS. Table 3 shows the results.

For both techniques, we extracted gelatin from bone samples according to the method described by Larsen et al. (1987). We made background corrections of the AMS dates by using the ${ }^{14} \mathrm{C}$ 
concentrations of bone gelatin (TUa-121) and wood (TUa-76), respectively. For the conventional dates, we determined counter background by using the standard background gas of marble from Fauske, Norway. Except for one sample (T-5112/TUa-120), where the ${ }^{14} \mathrm{C}$ concentration measured by GPC is higher than the AMS value, we found excellent agreement between the two dating techniques. Thus, no systematic discrepancy as reported by Beukens (1990) is found for samples prepared and dated in Trondheim.

TABLE 3. Interstadial Samples Measured by Both GPC and AMS

\begin{tabular}{lcccc}
\hline & \multicolumn{2}{c}{ GPC } & \multicolumn{2}{c}{ AMS } \\
\cline { 2 - 5 } Sample material & & & TUa** \\
no. & pMC \\
\hline Mammoth tooth, Toten, Norway & $2803 \mathrm{~A}$ & $0.43 \pm 0.20$ & 119 & $0.36 \pm 0.06$ \\
Whale bone, Svalbard & 5112 & $0.39 \pm 0.05$ & 120 & $0.13 \pm 0.04$ \\
Bird bones, Valderøya, Norway & 5156 & $2.51 \pm 0.25$ & 117 & $2.45 \pm 0.09$ \\
Whale bone, Svalbard & 8318 & $0.40 \pm 0.10$ & 118 & $0.39 \pm 0.06$ \\
IAEA C4, Kauri wood & 9153 & $0.37 \pm 0.10$ & 111 & $0.38 \pm 0.09$ \\
\hline
\end{tabular}

*Radiological Dating Laboratory, Trondheim

**A composite of $\mathrm{T}$ - Trondheim and Ua - Uppsala Accelerator Laboratory

\section{CONCLUSIONS}

Background materials for conventional ${ }^{14} \mathrm{C}$ measurements are normally not contaminated to a level that seriously affects dates on interstadial samples. However, we recommend fresh preparation of well-stored (dry, sealed) material.

AMS-sized carbonate samples are more vulnerable to contamination processes, probably related to the crystal structure of the actual material. Storage conditions are critical, especially for highly porous materials. The same may be true for wood of interglacial age.

Although background components contribute in different proportions for GPC and AMS dating, we have obtained good agreement for dates on interstadial bone and wood material.

\section{ACKNOWLEDGMENTS}

The authors wish to thank the staffs at the Trondheim and Uppsala laboratories, and in particular, the efforts of Fred H. Skogseth and Göran Possnert are appreciated. Valuable assistance from AGA $\mathrm{A} / \mathrm{S}$ made it possible to obtain the Matheson $\mathrm{CO}_{2}$ gas. Support from the Norwegian Research Council for Science and the Humanities (NAVF) is gratefully acknowledged.

\section{REFERENCES}

Beukens, R. P. 1990 High-precision intercomparison at IsoTrace. In Scott, E. M., Long, A. and Kra, R. S., eds., Proceedings of the International Workshop on Intercomparison of ${ }^{14} \mathrm{C}$ Laboratories. Radiocarbon 32 (3): 335-339.

Gulliksen, S. and Nydal, R. 1979 Further improvement of counter background and shielding. In Berger, R. and Suess, H. E., eds., Radiocarbon Dating. Proceedings of the 9th International ${ }^{14} \mathrm{C}$ Conference. Berkeley, University of California Press: 176-184.

Gulliksen, S., Nydal, R. and Løvseth, K. 1975 Trondheim natural radiocarbon measurements VII. Radiocarbon 17(3): 364-395.

Håkansson, S. 1980 Temperature dependent seasonal variation of the background in counters used for radiocarbon dating. In Stuiver, M. and Kra, R. S., eds., Proceedings of the 10 th International ${ }^{14} \mathrm{C}$ Conference. Radiocarbon 22(2): 448-454.

Hedges, R. E. M., Law, I. A., Bronk, C. R. and Housley, R. A. 1989 The Oxford accelerator mass spec- 
trometry facility: Technical developments in routine dating. Archaeometry 31: 99-113.

Larsen, E., Gulliksen, S., Lauritzen, S.-E., Lie, R., Løvlie, R. and Mangerud, J. 1987 Cave stratigraphy in western Norway; multiple Weichselian glaciations and interstadial vertebrate fauna. Boreas 16: 267292.

Possnert, G. 1990 Radiocarbon dating by accelerator technique. Norwegian Archaeological Review 23(12): 30-37.

Rozanski, K., Stichler, W., Gonfiantini, R., Scott, E. M., Beukens, R. P., Kromer, B. and Plicht, J. van der 1992 The IAEA ${ }^{14} \mathrm{C}$ Intercomparison Exercise 1990. In Long, A. and Kra, R. S., eds., Proceedings of the 14th International ${ }^{14} \mathrm{C}$ Conference. Radiocarbon, this volume.

Stafford, T. W., Jull, A. J. T., Brendel, K., Duhamel, R. C. and Donahue, D. 1987 Study of bone radiocarbon dating accuracy at the University of Arizona NSF accelerator facility for radioisotope analysis. Radiocarbon 29(1): 24-44.

Thomsen, M. S. and Gulliksen, S. 1992 Reduction of $\mathrm{CO}_{2}$-to-graphite conversion time of organic materials for ${ }^{14} \mathrm{C}$ AMS. In Long, A. and Kra, R. S., eds., Proceedings of the 14 th International ${ }^{14} \mathrm{C}$ Conference. Radiocarbon, this volume.

Vogel, J. S., Nelson, D. E. and Southon, J. R. $1987{ }^{14} \mathrm{C}$ background levels in an accelerator mass spectrometry system. Radiocarbon 29(3): 323-333.

Vogel, J. S., Southon, J. R., Nelson, D. E. and Brown, T. A. 1984 Performance of catalytically condensed carbon for use in accelerator mass spectrometry. In Wölfli, W., Polach, H. A. and Andersen, H. H., eds., Proceeding of the 3rd International Symposium on AMS. Nuclear Instruments and Methods B5: 289293. 